\title{
Weed seed choice by carabid beetles (Coleoptera: Carabidae): Linking field measurements with laboratory diet assessments
}

\author{
SAndrine PETIT, Aline BOURSAUlT and David A. BOHAN \\ INRA, UMR 1347 Agroécologie, BP 86510, F-21000 Dijon, France; e-mails: sandrine.petit2@dijon.inra.fr; \\ aline.boursault@gmail.com; david.bohan@dijon.inra.fr
}

\begin{abstract}
Key words. Coleoptera, Carabidae, granivory, biological regulation, selective feeding, agroecology, Viola arvensis, Capsella bursapastoris
\end{abstract}

\begin{abstract}
Carabid beetles could potentially provide a number of ecosystem services in arable fields, including the regulation of weeds by eating seeds. Spatio-temporal variability in the incidence of predation combined with a limited understanding of the interactions between carabids and seed predation, currently limits our ability to assess the effectiveness of this service. We carried out a long-term field study of carabid communities and the incidence of predation of the seeds of 5 species of weeds and laboratory cafeteria choicetests to quantify the preferences of the most abundant species of seed-eating carabid for the seeds of 10 species of weeds. The field study revealed important temporal variation both in carabid activity-density and seed predation, with the seed of Viola arvensis and Capsella bursa-pastoris being particularly preferred by the carabids. The laboratory cafeteria tests confirmed the predation preferences measured in the field, in showing strong preferences by both Pterostichus melanarius and Pseudoophonus rufipes for the seed of $V$. arvensis. The percentage predation of the seed of $V$. arvensis was associated with the activity-density of carabids, while that of the seed of $C$. bursapastoris was not. Integrating laboratory-measured daily consumption rates, per carabid taxa, into models improved the ability to predict the intensity of predation of the seed of $V$. arvensis based on the composition of carabid communities.
\end{abstract}

\section{INTRODUCTION}

Carabid beetles are potentially important bio-control agents in arable fields (Kromp, 1999) and as such could provide a number of services in agroecosystems such a slug control (Bohan et al., 2000) and regulation of aphids (Winder et al., 2005). Among the range of pests that could be regulated by carabids, arable weeds are a good candidate and a number of studies have determined that substantial numbers of seeds are consumed by carabids in the field (Tooley \& Brust, 2002; Honek et al., 2003). The predation of seeds could potentially affect the demography of individual weed species (Westerman et al., 2005) and indeed, a recent large-scale survey suggests that the turnover of weed seedbanks in individual fields is negatively associated with the abundance of carabids (Bohan et al., 2011). Despite such results, it remains difficult to assess whether weed seed predation can be considered as a service, the intensity, robustness and stability of which can be relied on as a partial or total substitute for weed management by herbicides.

A first limitation on our ability to predict the effectiveness of weed seed predation stems from the high variability in predation rates recorded in field studies. Weekly percentage predation of individual weed species, measured at a single location, typically vary between $10 \%$ and $80 \%$ from one week to the next (Westerman et al., 2003; Saska et al., 2008; Davis \& Raghu, 2010). Percentage predation also varies greatly between fields, whether these fields are located on different farms (Westerman et al., 2003) or close to one another (Saska et al., 2008). Although methods have been developed to estimate annual seed losses due to con- secutive predation events (Westerman et al., 2003; Davis et al., 2011), it is important to develop monitoring schemes that provide consistent results, both spatially and temporally, in order to account for the great variation in predation and identify those species of weeds that experience predation rates that are likely to affect their demography.

A second limitation is that trophic interactions occurring in the field between carabid beetles and weed seeds is poorly understood. Seed-eating carabid abundance is positively associated with seed predation (O'Rourke et al., 2006; Menalled et al., 2007; Trichard et al., 2013) at least as often as it is not (Mauchline et al., 2005; Saska et al., 2008; Davis \& Raghu, 2010; Gaines \& Claudio Gratton, 2010). The lack of a clear numerical response of carabids to the abundance of weed seed might result for the insufficient consideration of specific associations between carabids and weeds (Brooks et al., 2012). Results of assessing the diets of carabids in the laboratory indicate specific preferences for particular weeds (Cardina et al., 1996; Honek et al., 2006; White et al., 2007) that are stable over the activity period of carabid species (Honek et al., 2006). Several factors may affect preference, e.g. seed size relative to the size of the predator (Honek et al., 2007) or seed mass and seed coat strength (Lundgren \& Rosentrater, 2007). A number of studies have combined the assessment of carabid seed preferences in the laboratory with the results of monitoring carabid activity-density and rate of seed removal in the field. In some cases, knowledge of the feeding preferences of the main predators present in the field helped explain the seasonal variation in seed predation (Cardina et al., 1996) whereas in other cases, the rate of removal of the seed of particular species of weeds differed greatly from 
that expected based on the diet of the dominant species of carabids in the field (White et al., 2007).

In this study, we monitored concurrently carabid communities and weed seed predation levels during a winterwheat crop cycle in three fields located on the same farm and conducted laboratory experiments to quantify weed seed consumption and selection (preference) for or against ten specific weeds by the most abundant seed-eating carabid species sampled on the farm. Our objectives were two-fold: (i) to assess the spatio-temporal variation in both weed seed predation and carabid activity-density on the farm during the course of a wheat crop cycle; and, (ii) to evaluate if field measurements and laboratory measures of weed seed predation provide consistent results and (iii) to test whether knowledge of the quantitative consumption rates estimated in the laboratory can improve our ability to relate rates of predation of weed seeds to carabid communities in the field.

\section{MATERIAL AND METHODS}

\section{Field study}

The study was conducted on the experimental farm of INRA - Dijon - Epoisses (Côte d'Or, France; $47^{\circ} 20 \mathrm{~N}, 05^{\circ} 02 \mathrm{E}$ ) using a spatially nested design. We selected three 2 ha fields located $300 \mathrm{~m}$ apart. The 3 fields were sown with winter wheat between $20^{\text {th }}$ October and $8^{\text {th }}$ November 2009 and harvested during the first week of August 2010. There was no stubble-clearing after harvesting the crop and no herbicides or insecticides used during the experiment.

Within each field, twelve $2 \mathrm{~m} \times 3 \mathrm{~m}$ plots were set up $10 \mathrm{~m}$ apart along a transect that ran parallel to and $15 \mathrm{~m}$ from the field edge. Ten 1 week-long sampling sessions were carried out every other week from May until the end of September, with five during the crop growing period (pre-harvest) and five after harvesting the crop (post-harvest). Traps were only set in the weeks the field were sampled.

Carabid activity-density was measured using pitfall traps. The traps were plastic cups of $8.5 \mathrm{~cm}$ diameter, set into the ground and covered with a $14 \mathrm{~cm}$ diameter plastic roof. A single pitfall trap was positioned in the centre of each plot, with a total of 12 traps per field and 36 traps in the three fields. Because we intended to use trapped individuals to perform cafeteria tests in the laboratory, the traps were dry and emptied of their catches each day; no preservative liquid was used. Carabids were identified to species and the numbers of individuals trapped in each plot each week were summed for each of the sampling sessions.

Weed seed predation in each plot was assessed using 4 seed cards, one placed in each corner of a plot, exposed for the 7 days of the sampling session (after Westerman et al., 2003). Seed cards were made of pieces of sandpaper $(5.5 \mathrm{~cm} \times 14 \mathrm{~cm}$, grain size 80$)$ sprayed with repositionable glue (multi usage aerosol SADER) on which 20 seeds of each of five test species purchased from Herbiseed ${ }^{\circledR}$ (Twyford, Great Britain, www.herbiseed.com) were placed. These five species were selected because they occurred commonly on the farm; the decision to offer a diversity of species on a single card was made because in arable fields carabids are more likely to encounter a mixture of seeds than seeds of a single species. The five species differed in seed mass and were Capsella bursa-pastoris L. Medikus (0.1 mg;), Viola arvensis Murray (0.9 $\mathrm{mg}$ ), Alopecurus myosuroides Hudson (2.0 mg), Veronica hederaefolia L. (4.0 mg) and Galium aparine L. (6.9 mg). Seed cards were fixed to the ground and covered with a vertebrate exclosure cage (width $\times$ length $\times$ height $=10 \mathrm{~cm} \times 17.5 \mathrm{~cm} \times 3.75 \mathrm{~cm}$; mesh size $=1.25 \mathrm{~cm})$. In order to assess accidental weed seed loss (due to wind, rain or insufficient adhesive power of the glue), 8 seed cards were placed in each field in the $2^{\text {nd }}$ and $9^{\text {th }}$ plot and covered with a total exclosure cage of $1 \mathrm{~mm}$ wire mesh ("control cards"). Overall, a total of 144 test cards ( 4 per plot $\times 12$ plots $\times$ 3 fields) and 24 control cards ( $8 \times 3$ fields) were used to evaluate seed predation during each of the ten sampling sessions. An initial analysis of the results obtained during the measurement sessions showed that $V$. arvensis and $C$. bursa-pastoris were the most consumed species, therefore, we analyzed the results for these two species more thoroughly.

Predation rates for $V$. arvensis and C. bursa-pastoris were computed per plot and session using the following equation: $1-\left(\mathrm{N}_{\text {test }}\right.$ $\left./ \mathrm{N}_{\text {control }}\right) \cdot 100$, where $\mathrm{N}_{\text {test }}$ is the mean number of seeds remaining on the 4 test cards in each plot and $\mathrm{N}_{\text {control }}$ the mean number of seeds remaining on the control cards located in the corresponding field. Two-way nested ANOVA, on log-transformed number of seeds of $V$. arvensis and $C$. bursa-pastoris consumed, were done to assess the effect of spatial- (plot effect within a field; field effect) and temporal-scale (measurement session; pre-harvest and post-harvest) on predation.

\section{Diet of individual carabid species measured in the laboratory}

Tests were conducted for the species of carabids that were most abundant in the field. Individuals collected in the field were kept for 3-5 days in the dark, at $5^{\circ} \mathrm{C}$, in order to standardize their level of starvation. The cafeteria test arena consisted of a large Petri dish $($ diameter $=18 \mathrm{~cm}$, depth $=4 \mathrm{~cm})$, filled with $2 \mathrm{~cm}$ of moist soil and devoid of seeds or animal prey (see Honek et al., 2006). The arenas were kept in a climatic chamber at $25^{\circ} \mathrm{C}$ and natural photoperiod over the period of testing. Seed were presented in 10 small round trays $(28 \mathrm{~mm}$ diameter $\times 6 \mathrm{~mm}$ height $)$ filled with white plasticine (JOVI ${ }^{\circledR}$, Barcelona). These we placed, equally spaced, against the outer edge of the arena. One tray contained $V$. arvensis seed, a second C. bursa-pastoris seed and the eight other trays contained seed of eight other species, which varied in size [Senecio vulgaris L. (0.2 mg), Taraxacum officinale Weber $(0.7 \mathrm{mg})$, Cirsium arvense (L.) Scop. (1.3 mg), Alopecurus myosuroides Hudson (2.0 mg), Fallopia convolvulus (L.) Á. Löve (3.2 mg), Veronica hederaefolia, L. (4.0 mg), Galium aparine L. $(6.9 \mathrm{mg})$ and Fumaria officinalis L. $(8.9 \mathrm{mg})]$. The seed of the different species was randomly assigned to the round trays for the tests. Each test lasted for 5 days and each day, consumed seeds were replaced in order to keep the seed offer constant.

Daily predation was summed over the five days and averaged to obtain a standardized daily consumption, in an attempt to control for hypothetical biases in predation, due to dish adaptation (under consumption) or restricted area adaptation (hyper consumption of seeds after an under consumption period). By averaging standardized consumption of the $n$ individuals tested per carabid species, we obtained a daily predation per carabid taxa for $V$. arvensis and C. bursa-pastoris, as well as for the other eight species of weeds. A two-way nested ANOVA was performed to assess the importance of the trophic guild and within-guild effects on the rates of consumption of $V$. arvensis and C. bursa-pastoris seed.

To fully explore weed seed choice by predators, we computed Manly's $\alpha$ (Manly et al., 1972), a preference index that separates the effect of the selective behaviour of predators from that of the relative frequencies of prey available (Chesson, 1978; Roberts \&

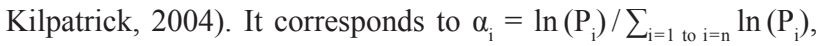
where $P_{i}$ is the rate of predation of the seed of each species of weed i. A mean value and standard deviation for Manly's $\alpha$ was computed per carabid species for the ten weed species. A non- 

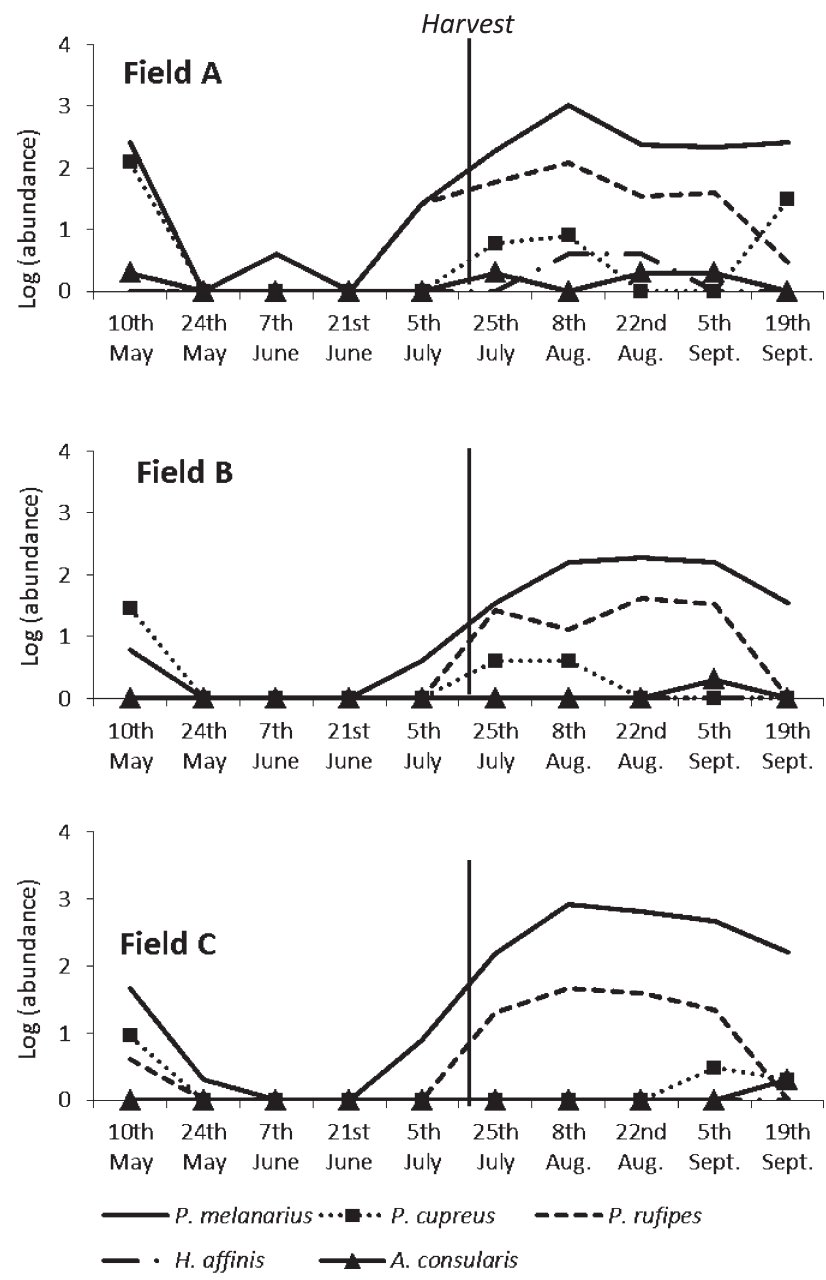

Fig. 1. Abundance of the most abundant species of carabids ( $\log$ values) recorded in the three fields on 10 dates in 2010.

selective behaviour would correspond here to a value of $\alpha=1 / 10$ $=0.1$ as seed of 10 species of weeds were offered to the predators. A value above 0.1 suggests a preference for the seed a particular species of weed while a value below 0.1 suggests avoidance.

\section{Linking carabids with the predation rates recorded in the field using laboratory diet assessments}

The link between carabid activity-density and predation rates was explored using generalised linear regression models (GLM), with a quasi-binomial link to account for the overdispersion in the observed proportional data (Crawley, 2013). Models were developed for the log-transformed carabid counts for total activitydensity for all seed-eating carabids and for individual species of carabid. A comparison was also made of the goodness of fit of a model that related recorded rates of predation with linear combinations of activity-density for individual species of carabid ("pure activity-density" model) with that of one in which the linear combinations of individual species of carabid were weighted by their daily consumption, which was measured in the laboratory ("consumption" model). The goodness of fit of the models was scrutinized by checking the model standardized residuals for normality and evidence of systematic variation. The "pure activity-density" and the "consumption" models were compared using an F-test of the difference in the deviance explained with one degree of freedom.

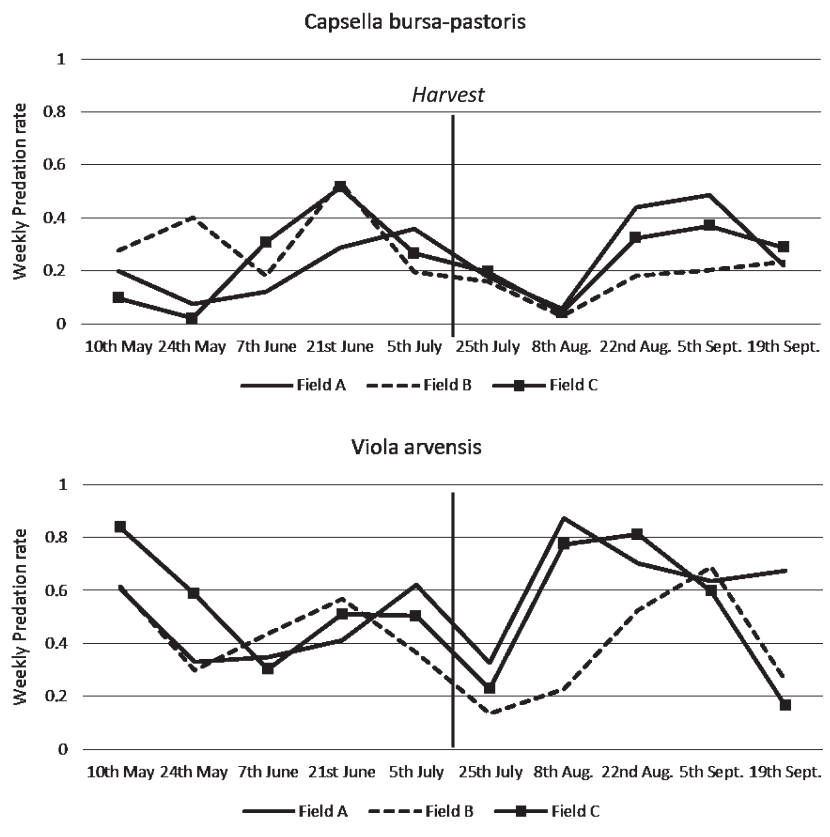

Fig. 2. Incidence of predation of the seeds of $C$. bursa-pastoris and $V$. arvensis recorded in three fields on 10 dates in 2010.

\section{RESULTS}

\section{Weed seed predation and carabids on the farm}

A total of 6203 carabids belonging to 11 species/taxa were collected during the course of this study. The dominant species, in order of abundance, were Pterostichus melanarius Illiger, 1798; Pseudoophonus rufipes De Geer, 1774; Agonum dorsale Pontoppidan, 1763; Poecilus cupreus Linnaeus, 1758; Trechus quadristriatus Schrank, 1781; Amara consularis Duftschmid, 1812 and Harpalus affinis Schrank, 1781. The species composition was similar in the three fields, with $P$. melanarius consistently the most abundant (Fig. 1), but there were differences in terms of overall carabid activity-density per field. Total carabid catches over the course of this study were 2892, 786 and 2525 individuals in Fields A, B and C, respectively. Temporally, there were two peaks of carabid activity-density in the three fields, the first in April-May and second in August-September.

Mean percentage predation was $24 \pm 18.8 \%$ for C. bursa-pastoris and $50 \pm 27.5 \%$ for $V$. arvensis (Fig. 2) and was lower for the other three species offered on the predation cards, with overall percentage predation ranging from 16 to $22 \%$. Percentage predation for C. bursa-pastoris (CBP) and $V$. arvensis (VA) varied according to when measured $\left(\mathrm{F}_{\mathrm{CBP}}=21.91, \mathrm{p}<0.001 ; \mathrm{F}_{\mathrm{VA}}=3.91, \mathrm{p}<0.05\right)$ but did not differ before and after harvest $\left(\mathrm{F}_{\mathrm{CBP}}=2.18, \mathrm{~ns} ; \mathrm{F}_{\mathrm{VA}}=0.43\right.$, $\mathrm{ns})$. In terms of spatial variation, there was no plot effect $\left(\mathrm{F}_{\mathrm{CBP}}=0.75, \mathrm{~ns} ; \mathrm{F}_{\mathrm{VA}}=0.90, \mathrm{~ns}\right)$ but a field effect for $V$. arvensis $\left(\mathrm{F}_{\mathrm{CBP}}=0.01\right.$, ns; $\left.\mathrm{F}_{\mathrm{VA}}=9.51, \mathrm{p}<0.01\right)$.

\section{Consumption of weed seeds by carabids recorded in the laboratory}

Tests were performed using the five most abundant seedeating carabid taxa collected in the fields, which belonged to two trophic guilds, two omnivores ( $P$. melanarius and 
TABLE 1. Mean and standard deviation for the laboratory daily consumption. $\mathrm{n}$ - number of individuals tested, "+" - mean daily consumption less than 0.01 seed.

\begin{tabular}{lccccc}
\hline & $\begin{array}{c}\text { P. melanarius } \\
\mathrm{n}=31\end{array}$ & $\begin{array}{c}\text { P. cupreus } \\
\mathrm{n}=48\end{array}$ & $\begin{array}{c}\text { A. consularis } \\
\mathrm{n}=27\end{array}$ & $\begin{array}{c}\text { H. affinis } \\
\mathrm{n}=26\end{array}$ & $\begin{array}{c}\text { H. rufipes } \\
\mathrm{n}=27\end{array}$ \\
\hline Fumaria officinalis $(8.9 \mathrm{mg})$ & + & + & $0.16(0.53)$ & + & + \\
Galium aparine $(6.9 \mathrm{mg})$ & + & + & + & + & + \\
Veronica hederaefolia $(4.0 \mathrm{mg})$ & + & + & + & + & + \\
Fallopia convolvulus $(3.2 \mathrm{mg})$ & + & + & $0.2(0.40)$ & + & + \\
Alopecurus myosuroides $(2.0 \mathrm{mg})$ & $0.06(0.18)$ & $0.05(0.11)$ & + & $0.12(0.42)$ & $0.40(0.46)$ \\
Cirsium arvense $(1.3 \mathrm{mg})$ & $0.23(0.1)$ & $0.41(0.1)$ & $0.54(1.22)$ & $1.78(1.54)$ & $4.43(3.46)$ \\
Viola arvensis $(0.9 \mathrm{mg})$ & $0.15(0.24)$ & $0.40(0.62)$ & $0.55(1.31)$ & $4.65(3.13)$ & $15.37(6.06)$ \\
Taraxacum officinale $(0.7 \mathrm{mg})$ & $0.12(0.26)$ & $1.12(3.04)$ & $3.24(4.31)$ & $2.52(2.90)$ & $4.34(2.89)$ \\
Senecio vulgaris $(0.2 \mathrm{mg})$ & $0.17(0.33)$ & $1.87(3.83)$ & $2.18(4.77)$ & $1.12(2.35)$ & $1.02(1.28)$ \\
Capsella bursa-pastoris $(0.1 \mathrm{mg})$ & $0.46(1.06)$ & $1.40(2.58)$ & $4.71(6.02)$ & $1.57(3.31)$ & $0.77(0.70)$ \\
\hline Daily seed consumption & 1.28 & 5.26 & 11.62 & 11.82 & 26.35
\end{tabular}

P. cupreus) and three granivores (P. rufipes, H. affinis and A. consularis). Overall, the daily consumption of weeds seeds by these carabids differed greatly (Table 1$)$. The most preferred seeds were those of $V$. arvensis (21.12 seeds per day), Taraxacum officinale (11.34), C. bursa-pastoris (8.91), Cirsium arvense (7.39) and Senecio vulgaris (6.36). The seeds of the other five weed species were rarely eaten, i.e. less than 1 seed daily.

The daily consumption of the seed of $C$. bursa-pastoris differed with carabid trophic guild, i.e. between omnivores and granivores $(\mathrm{F}=8.87 ; \mathrm{p}<0.001)$ and by species within a given trophic guild $(\mathrm{F}=9.42 ; \mathrm{p}<0.001)$, with $A$. consularis the most important predator. Given the inter-individual variation in the choice of seed of C. bursa-pastoris, the preference indices were not statistically different from expected based on random choice. The daily consumption of $V$. arvensis varied between carabid trophic guilds $(\mathrm{F}=$ $16.2, \mathrm{p}<0.001)$ and between species within guilds $(\mathrm{F}=$ $16.7, \mathrm{p}<0.001)$. Preference indices indicate that both $P$. rufipes (mean $\alpha=0.62, \mathrm{SD}=0.17$ ) and $H$. affinis (mean $\alpha=$ $0.47, \mathrm{SD}=0.33$ ) preferred seed of $V$. arvensis. Conversely, $P$. rufipes (mean $\alpha=0.02, \mathrm{SD}=0.07$ ) and $H$. affinis (mean $\alpha=0.02, \mathrm{SD}=0.07$ ) clearly avoided the seeds of $A$. myosurides.

\section{Relating percentage predation to carabids}

The percentage predation of seed of C. bursa-pastoris measured in the field was not statistically related to the activity-density of carabids, measured in terms of total number of seed-eaters or the activity-density of individual species of carabid (Table 2). Weighting the activity-density of each carabid species by the daily percentage consump- tion estimated in the laboratory did not yield a significant improvement in explanation when compared to a model using total activity-density of seed-eating carabids $\left(\mathrm{F}_{1,349}\right.$ $=3.24, \mathrm{p}>0.05)$. Recorded percentage predation of seed of $V$. arvensis was positively related to the activity-density of carabids that consume seeds, and particularly to the activity-density of the granivore $P$. rufipes and omnivore $P$. melanarius. The large differences in the daily percentage consumption of seed of $V$. arvensis by different carabid species in the laboratory (Table 1), when used as weights for the activity-density of carabids, did improve the fit of the "consumption" model over the "pure activity-density" model $\left(\mathrm{F}_{1,349}=31.35, \mathrm{p}<0.001\right)$.

\section{DISCUSSION}

\section{Spatial and temporal patterns in carabid activity- density and weed seed predation}

Spatial variations in carabid community composition and weed seed predation patterns are widely reported in the literature, with studies comparing these patterns in fields with the same crop and located very close geographically (Westerman et al., 2003; Saska et al., 2008). In this study, carabid activity-density and percentage predation were more or less consistent within and among the fields monitored. The composition of carabid communities was comparable in the three fields, although abundances tended to be higher in one of them. Seed predation also followed a common general pattern in the three fields, although a field effect was detected for seed of $V$. arvensis, with a noticeably lower post-harvest percentage predation in one of the fields. This relative homogeneity is probably

TABLE 2. Results of GLM relating observed predation rates of $C$. bursa-pastoris and $V$. arvensis to carabid counts. Observed predation rates are related to the activity-density of individual carabid species.

\begin{tabular}{|c|c|c|c|c|c|c|c|c|c|c|}
\hline \multirow[b]{2}{*}{$\begin{array}{l}\text { Individual } \\
\text { carabid species }\end{array}$} & \multicolumn{5}{|c|}{ C. bursa-pastoris } & \multicolumn{5}{|c|}{ V. arvensis } \\
\hline & estimate & $t$-value & $p$-value & F-value & $\begin{array}{c}\% \text { variation } \\
\text { explained }\end{array}$ & estimate & $t$-value & $p$-value & F-value & $\begin{array}{c}\% \text { variation } \\
\text { explained }\end{array}$ \\
\hline P. rufipes & -1.41 & 1.86 & ns & $\mathrm{F}_{1,348}=2.40$ & 0.62 & 0.65 & 1.33 & ns & $\mathrm{F}_{1,348}=22.02$ & 5.41 \\
\hline H. affinis & 0.06 & 0.05 & ns & $\mathrm{F}_{1,351}=0.00$ & 0.00 & 1.14 & 0.61 & ns & $\mathrm{F}_{1,351}=4.41$ & 1.14 \\
\hline A. consularis & -1.35 & 1.07 & ns & $\mathrm{F}_{1,349}=0.52$ & 0.14 & -0.74 & 0.59 & ns & $\mathrm{F}_{1,349}=0.00$ & 0.00 \\
\hline P. melanarius & -0.58 & 2.66 & 0.008 & $\mathrm{~F}_{1,348}=6.73$ & 1.70 & 0.39 & 2.30 & 0.022 & $\mathrm{~F}_{1,348}=26.77$ & 6.30 \\
\hline P. cupreus & -0.62 & 0.94 & ns & $\mathrm{F}_{1,348}=1.19$ & 0.31 & 0.43 & 0.93 & ns & $\mathrm{F}_{1,348}=5.06$ & 1.30 \\
\hline
\end{tabular}


related to the fact that the three winter-wheat fields were managed identically, located close geographically and did not clearly differ in terms of environmental conditions, e.g. soil properties.

Conversely, strong temporal variations in carabid activity-density and percentage seed predation were detected. Carabid activity-density was high in May, low before harvest and increased dramatically post-harvest. Seed predation patterns showed three peaks, one in May, which coincided with a peak of activity of carabids, notably the two omnivores $P$. melanarius and $P$. cupreus, one in early summer, reported in other studies (Westerman et al., 2003; Saska et al., 2008) and one post-harvest peak, which coincided with a high activity-density of the omnivore $P$. melanarius and granivore $P$. rufipes. The temporal variations in carabid activity-density observed here may partly reflect variations in carabid density but caution is required in the interpretation of pitfall trapping data as it could be affected by temporal variations in the mobility and/or catchability of carabids (Baars, 1979; Thomas et al., 1998). Here, the mobility of carabids may have been reduced because of the high levels of seed consumption recorded in early summer, before the harvest, i.e. low carabid activity-density coincided with a peak in seed predation, and possibly also the availability of alternative prey. At the same time, the important increase in the activity-density of $P$. melanarius after harvest, although coinciding with a peak in seed predation, could reflect an overall food scarcity in the fields, i.e. individuals were hungry and walked greater distances to meet their dietary needs. Such limitations on the interpretation of carabid activity-density data may partly explain the lack of clear spatial and temporal associations with patterns in seed predation (Saska et al., 2008; Trichard et al., 2014) and more widely between predators and prey (Winder et al., 2005).

\section{Consumption of seed of individual species of weeds}

The laboratory diet assessments revealed that not all seeds of the different species of weeds are equally consumed by carabids. Interestingly the ranking of consumption in the laboratory matched our field observations. In the field and laboratory, the seeds of $V$. arvensis and $C$. bursa-pastoris were the most consumed, which confirms results of studies conducted in different European countries (Goldsmith \& Toft, 1997, Tooley \& Froud-Williams, 1999; Honek et al., 2003; Saska et al., 2008). The consumption of the seed of these two species was also consistently high during this study, which is in accordance with laboratory experiments showing that seed preference patterns of individual carabid species is constant at least during a cropping season and maybe longer (Honek et al., 2006). Indeed, the marked preference for the seed of $V$. arvensis was also previously recorded on this farm (Alignier et al., 2008; Meiss et al., 2010). It is difficult to account for the high consumption of $V$. arvensis seed. In this study Harpalus affinis and $H$. rufipes selected the seed of $V$. arvensis in the laboratory, which is in accordance with previous cafeteria test results (Honek et al., 2006). When looking at the overall pattern of weed seed consumption, our field and laboratory results are consistent with an order of preference determined by seed size (Honek et al., 2007). Seeds that exceeded $3 \mathrm{mg}$ in weight (i.e. $G$. aparine and $V$. hederifolia) were rarely consumed in the laboratory and the field. There were, however, differences in the consumption of small seeds. The Manly $\alpha$-preference indices indicate that strong preference of carabids for particular species, in our case the seed of $V$. arvensis, while that of $C$. bursa-pastoris was neither preferred or avoided. This might be explained by differences in the energy content of weed seeds (both $C$. bursa-pastoris and $V$. arvensis have lipid-rich seeds) and also by differences in the thickness and hardness of the seed coat of individual species (Honek et al., 2003; Lundgren \& Rosentrater, 2007), a seed attribute that is poorly documented in the literature. Finally, seed choice could be affected by the history of individual predators and previous encounters with weed seed. In our case, $V$. arvensis seed was the most abundant seed available on the soil surface in the fields monitored (data not presented here) while that of C. bursa-pastoris was rarely present. This discrepancy might explain why $V$. arvensis was by far the most consumed seed, while C. bursa-pastoris was less frequently eaten in the field.

\section{Predicting levels of weed seed predation based on carabid data}

Previous attempts to link weed seed predation levels with the activity-density of carabid beetles have led to conflicting results and among the possible causes of the mismatches, the problems associated with the interpretation of carabid activity-density data that are highlighted above. Here, we combined laboratory diet assessments with field studies in order to achieve a clearer interpretation of field results. No statistical link could be detected between carabid activity density and percentage predation of the seed of $C$. bursa-pastoris. Conversely, $V$. arvensis seed predation was associated with the activity-density of seed-eating carabids and the models developed to test for specific associations showed that the level of predation of seed of $V$. arvensis was positively associated with the activity-densities of both $P$. melanarius, and $P$. rufipes. The omnivore $P$. melanarius most probably did not consume a large amount of seed in the field, given that its overall daily consumption of seed was very low in the laboratory (1.28 seeds a day, of which 0.15 were seeds of $V$. arvensis). However, because thousands of individuals were present in the fields during the experiment, the species may still have had an effect on the level of weed seed predation. That $P$. melanarius abundance affects the rate at which the weed seed bank is depleted has been shown in a previous study (Bohan et al., 2011), presumably for similar reasons. For P. rufipes, laboratory diet assessment suggests strong preference for seeds of $V$. arvensis, with daily consumption averaging 15 seeds per day. It is thus likely that such a strong preference makes it possible to detect predation by P. rufipes, despite the relatively low abundance of this granivorous species.

To conclude, our results confirm that only a limited number of weeds are likely to be regulated by carabids. Seeds of some weeds, such as $V$. arvensis, appear to be targeted 
by these invertebrate predators, from early spring to early autumn. This association may explain why the seed consumption of this species recorded using seed cards could be related to the activity-density of carabids, while for a least preferred, but well-consumed species, such as $C$. bursa-pastoris, no such link could be established.

ACKNOWLEDGEMENTS. The authors thank the staff of the INRA Epoisses experimental farm for adjusting farming practices to fit in with the requirements of this experiment. The experiment was funded through the project ANR SYSTERRA ADVHERB (ANR-08-STRA-02) and A. Boursault benefited from a studentship from the French ministry of Research.

\section{REFERENCES}

Alignier A., Meiss H., Petit S. \& Reboud X. 2008: Variation of post-dispersal weed seed predation according to weed species, space and time. - J. Plant Dis. Protect. 21: 221-226.

BAARs M.A. 1979: Catches in pitfall traps in relation to mean densities of carabid beetles. - Oecologia 41: 25-46.

Bohan D.A., Bohan A., Glen D.M., Symondson W.O.C. \& WittSHIRE C. 2000: Spatial dynamics of predation by carabid beetles on slugs. - J. Anim. Ecol. 69: 367-379.

Bohan D.A., Boursault A., Brooks D. \& Petit S. 2011: National-scale regulation of the weed seedbank by carabid predators. —J. Appl. Ecol. 48: 388-398.

Brooks D.R., Storkey J., Clark S.J., Firbank L.G., Petit S. \& WorwoD I.P. 2012: Trophic links between functional groups of arable plants and beetles are stable at a national scale. $-J$. Anim. Ecol. 81: 4-13.

Cardina J., Norquay H.M., Stinner B.R. \& McCartney D.A. 1996: Postdispersal predation of velvetleaf (Abutilon theophrasti) seeds. — Weed Sci. 44: 534-539.

CHEsson J. 1978: Measuring preference in selective predation. Ecology 59: 211-215.

Crawley M.J. 2013: The R Book, 2nd ed. John Wiley and Sons, Chichester, $1076 \mathrm{pp}$.

Davis A.S. \& Raghu S. 2010: Weighing abiotic and biotic influences on weed seed predation. - Weed Res. 50: 402-412.

Davis A.S., Deadlow D., Schutte B.J. \& Westerman P.R. 2011: Temporal scaling of episodic point estimates of seed predation to long-term predation rates. - Meth. Ecol. Evol. 2: 682-690.

Gaines H.R. \& Claudio Gratton C. 2010: Seed predation increases with ground beetle diversity in a Wisconsin (USA) potato agroecosystem. - Agric. Ecosyst. Environ. 137: 329-336.

Goldsmith H. \& Toft S. 1997: Variable degrees of granivory and phytophagy in insectivorous carabid beetles. - Pedobiologia 41: $521-525$.

Honek A., Martinkova Z. \& Jarosik V. 2003: Ground beetles (Carabidae) as seed predators. Eur. J. Entomol. 100: 531-544.

Honek A., SASKa P. \& Martinkova Z. 2006: Seasonal variation in seed predation by adult carabid beetles. - Entomol. Exp. Appl. 118: $157-162$.

Honek A., Martinkova Z., Saska P. \& Pekar S. 2007: Size and taxonomic constraints determine the seed preferences of Carabidae (Coleoptera). - Basic Appl. Ecol. 8: 343-353.

Kromp B. 1999: Carabid beetles in sustainable agriculture: a review on pest control efficacy, cultivation impacts and enhancement. - Agric. Ecosyst. Environ. 74: 187-228.
Lundgren J.G. \& Rosentrater K.A. 2007: The strength of seeds and their destruction by granivorous insects. - ArthropodPlant Interact. 1: 93-99.

Manly B.F.J., Miller P. \& CoOK L.M. 1972: Analysis of a selective predation experiment. - Am. Nat. 106: 719-736.

Mauchline A.L., Watson S.J., Brown V.K. \& Froud-Williams R.J. 2005: Post-dispersal seed predation of non-target weeds in arable crops. - Weed Res. 45: 157-164.

Meiss H., Lagadec L., Munier-Jolain N., Waldhardt R. \& Petit S. 2010: Weed seed predation increases with vegetation cover in perennial forage crops. - Agric. Ecosyst. Environ. 138: $10-16$.

Menalled F.D., Smith R.G., Dauer J.T. \& Fox T.B. 2007: Impact of agricultural management on carabid communities and weed seed predation. - Agric. Ecosyst. Environ. 118: 49-54.

O’Rourke M.E., Heggenstaller A.H., Liebman M. \& Rice M.E. 2006: Post-dispersal weed seed predation by invertebrates in conventional and low-external-input crop rotation systems. Agric. Ecosyst. Environ. 116: 280-288.

Roberts J.H. \& Kilpatrick J.M. 2004: Predator feeding preferences for a benthic stream fish: Effects of visible injected marks. - J. Freshw. Ecol. 19: 531-538.

Saska P., Van der Werf W., de Vries E. \& Westerman P.R. 2008: Spatial and temporal patterns of carabid activity-density in cereals do not explain levels of predation on weed seeds. - Bull. Entomol. Res. 98: 169-181.

Thomas C.F.G., Parkinson L., Marshall E.J.P. 1998: Isolating the components of activity-density for the carabid beetle Pterostichus melanarius in farmland. - Oecologia 116: 103112.

Tooley J.A. \& Brust G.E. 2002: Weed seed predation by carabid beetles. In Holland J.M. (ed.): The Agroecology of Carabid Beetles. Intercept, Andover, pp. 215-229.

Tooley J.A. \& Froud-Williams R.J. 1999: Weed seed predation in arable field margins by carabid beetles (Carabidae: Coleoptera). - Aspects Appl. Biol. 54: 211-216.

Trichard A., Alignier A., Biju-Duval L. \& Petit S. 2013: The relative effects of local management and landscape context on weed seed predation and carabid functional groups. - Basic Appl. Ecol. 14: 235-245.

Trichard A., Ricci B., Ducourtieux C. \& Petit S. 2014: The spatio-temporal distribution of weed seed predation differs between conservation agriculture and conventional tillage. Agric. Ecosyst. Environ. 180: 40-47.

Westerman P.R., Wes J.S., Kropff M.J. \& Van der Werf W. 2003: Annual losses of weed seeds due to predation in organic cereal fields. - J. Appl. Ecol. 40: 824-836.

Westerman P.R., Liebman M., Menalled F.D., Heggenstaller A.H., Hartzler R.G. \& Dixon P.M. 2005: Are many little hammers effective? Velvet leaf (Abutilon theophrasti) population dynamics in two- and four-year crop rotation systems. - Weed Sci. 53: 382-392.

White S.S., Renner K.A., Menalled F.D. \& Landis D.A. 2007: Feeding preferences of weed seed predators and effect on weed emergence. - Weed Sci. 55: 606-612.

Winder L., AleXander C.J., Holland J.M., Symondson W.O., Perry J.N. \& Woolley C. 2005: Predatory activity and spatial pattern: the response of generalist carabids to their aphid prey. -J. Anim. Ecol. 74: 443-454.

Received December 16, 2013; revised and accepted August 11, 2014 Prepublished online September 22, 2014 